\title{
Molecular - Docking Studies of Potent Anticancer Agent
}

Heena V Sanghani ${ }^{1 *}$, Sunil H Ganatra ${ }^{2}$ and Rama Pande ${ }^{2}$

${ }^{1}$ Assistant Professor Sinhgad College of Engineering, Vadgaon, Pune, India

${ }^{2}$ Department of Chemistry Institute of Science, Nagpur, SOS Pt. Ravishankar Shukla University Raipur, India

\begin{abstract}
Cyclin dependent kinases are critical molecules that control cell cycle progression from one phase to the other. However, mutational changes in these molecules lead to the purturbed cell cycle leading to uncontrolled cellular proliferation or cell death. In humans, mutations in cyclin dependent kinase 2 (1GII) is responsible for nearly $50 \%$ of cancers. In this paper preliminary in-silico screening were performed of natural polytriterpene phytochemical that are thought to have potential to inhibit mutated $1 \mathrm{GII}$. Out of the two triterpenes boswellic acid and ursolic acid, boswellic acid shows inhibition activity with $1 \mathrm{GII}$. From this study we propose that boswellic acid is promising towards oral cancer than ursolic acid.
\end{abstract}

Keywords: CDK2, Cyclin dependent kinase; Molecular-docking; Ligand-docking; Ligand protein interactions binding affinity; Structure-based drug design; Boswellic acid; Ursolic acid

\section{Introduction}

Cancer is one of the most dreaded diseases of the $20^{\text {th }}$ century and spreading further with continuance and increasing incidence in 21 st century. It is a group of disease characterized by uncontrolled cell-division leading to abnormal growth of the tissue. Each year 6.7 million people worldwide die from Cancer. Globally around 270000 new cases occur annually and 145000 deaths, of which two-thirds occur in developing countries [1]. It is considered as an adversary of modernization and advanced pattern of socio-cultural life dominated by western medicine. Multidisciplinary scientific investigations are making best efforts to combat this disease, but the sure-shot, perfect cure is yet to be brought into world medicine.

Recently, a greater emphasis has been given towards the researches on complementary and alternative medicine that deals with cancer management. Several studies have been conducted on herbs under a multitude of ethno botanical grounds. For example, Hartwell [210] has collected data on about 3000 plants, those of which possess anticancer properties and subsequently been used as potent anticancer drugs [11]. Ayurveda, a traditional Indian medicine of plant drugs has been successful from very early times in using these natural drugs and preventing or suppressing various tumors using various lines of treatment. Natural products from anticancer herbs were selected for studies which are triterpenes acids like boswellic acid and ursolic acid.

Natural products have historically and continually been investigated for promising new leads in pharmaceutical development. New anticancer drugs derived from research on plant, antitumor agents will be continuously discovered. Natural Product boswellic acid is a pentacyclic triterpenes and its derivatives are effective for human leukemia HL-60 cell culture inhibited DNA synthesis in HL-60 cells in a dose-dependent manner with $\mathrm{IC}_{50}$ values ranging from 0.6 to 7.1 $\mu \mathrm{M}$. The results indicate that $\beta$-boswellic acid and its derivatives (the major constituents of Boswellin) have anti-carcinogenic, anti-tumor, and anti-hyperlipidemic activities [12].

Ursolic acid is a pentacyclic triterpenes which is widely used in the area of oncology because of its cytotoxicity induction of differentiation, anti-mutagenic, antiviral and anti-invasive activities. Ursolic Acid is capable of inducing apoptosis in tumor cells on one side and to prevent malignant transformation of normal cells on the other side. It also interferes with numerous enzymes, including the ones serving directly to DNA synthesis. It is also known that ursolic acid is biological properties and shows its main anti-tumor effects and chemo preventive properties in normal cells $[13,14]$.

The side effects of synthetic drugs make the need for the necessity of new improved drugs. Biological activities shows that triterpenes boswellic acid and ursolic acid promising anticancer phytochemicals. Thus, in our research study we tried to find the binding affinity, which could be a possible lead molecule. Computational Biology and bioinformatics have the potential not only of speeding up the drug discovery process thus reducing the costs, but also of changing the way drugs are designed. Rational Drug Design (RDD) helps to facilitate and speed up the drug designing process, which involves variety of methods to identify novel compounds. One such method is the docking of the drug molecule with the receptor (target). The site of drug action, which is ultimately responsible for the pharmaceutical effect, is a receptor (Richon, 1994). In the field of molecular modeling, docking is a method which predicts the preferred orientation of one molecule to a second when bound to each other to form a stable complex. Knowledge of the preferred orientation in turn may be used to predict the strength of association or binding affinity between two molecules. Docking is frequently used to predict the binding orientation of small molecule drug candidates to their protein targets in order to in turn predict the affinity and activity of the small molecule.

\section{Materials and Methods}

\section{Materials}

For our present study we used biological databases like PubChem, Drug Bank, PDB (Protein Data Bank) and software's like Arguslab

*Corresponding author: Heena V. Sanghani, Assistant Professor in Engineering Chemistry, Sinhgad College of Engineering, Vadgaon (Bk), Pune, Tel: 91 9822369793; E-mail: sanghaniheena@yahoo.com

Received September 20, 2011; Accepted January 25, 2012; Published January 27, 2012

Citation: Sanghani HV, Ganatra SH, Pande R (2012) Molecular -Docking Studies of Potent Anticancer Agent. J Comput Sci Syst Biol 5: 012-015. doi:10.4172/ jcsb. 1000085

Copyright: (c) 2012 Sanghani HV, et al. This is an open-access article distributed under the terms of the Creative Commons Attribution License,which permits unrestricted use, distribution, and reproduction in any medium, provided the original author and source are credited. 
Citation: Sanghani HV, Ganatra SH, Pande R (2012) Molecular -Docking Studies of Potent Anticancer Agent. J Comput Sci Syst Biol 5: 012-015. doi:10.4172/jcsb. 1000085

and Chemdraw. The PDB (Protein Data Bank) is the single worldwide archive of Structural data of Biological macromolecules, established in Brookhaven National Laboratories (BNL) in 1971(The Protein Data Bank, 2000). It contains Structural information of the macromolecules determined by X-ray crystallographic, NMR methods etc. Arguslab offers quite good on-screen molecule-building facilities, with a moderate library of useful molecules. It is a free molecular modeling package that runs under Windows (Thompson, 2004).

\section{Methodology}

Preparation of protein structure: Bioinformatics is seen as an emerging field with the potential to significantly improve how drugs are found, brought to the clinical trials. Protein target were downloaded from database Protein Data Bank (PDB). (PDB: http://www.rcsb.org/ $\mathrm{pdb} /$ home/home.do) $1 \mathrm{GII}$ is PDB id of the target protein. All water molecules were removed and on final stage hydrogen atoms were added to receptor molecule.

Preparation of ligand structure: Two natural products were selected as ligand considering their biological activities. Boswellic acid and ursolic acid are pentacyclic triterpenes which show biological activities as shown in following table1.

The 3D structures of these two phytochemicals were obtained by using "Chemdraw". The docking analysis of Boswellic acid and ursolic acid and human cyclin dependent kinase 2 receptor was carried by Arguslab docking software. Docking allows virtually screening a database compounds and predicting the strongest binders based on their scoring functions. It explores ways in which two molecules, such as drugs and an enzyme human cyclin dependent kinase 2 receptor fit together and dock each other well. The molecules binding to a receptor, inhibit its function, and thus act as a drug [15]. Boswellic acid and ursolic acid and receptor were identified via docking and their relative stabilities were evaluated using molecular dynamics and their binding affinities using free energy simulations. Boswellic acid and ursolic acid were docked against the same receptor using parameters by default in ArgusLab software.

Protein ligand interaction using ArgusLab 4.0.1: Argus Lab is the electronic structure program that is based on the quantum mechanics, it predicts the potential energies, molecular structures; geometry optimization of structure, vibration frequencies of coordinates of atoms, bond length, bond angle and reactions pathway [16].

CDK protein receptor was docked against the obtained two ligands obtained using ArgusLab 4.0.1 to find the reasonable binding geometries and explore the protein ligand interactions. Docking of the protein ligand complex was mainly targeted only on to the predicted active site. Docking simulations were performed by selecting "ArgusDock" as the docking engine. The selected residues of the receptor were defined to be a part of the binding site.

Interaction studies: The goal of ligand-protein docking is to predict the predominant binding model(s) of a ligand with a protein of known three dimensional structure. To study the binding modes of bioactive

\begin{tabular}{|l|l|}
\hline Name of Compound & Biological activity (IC50 value) \\
\hline Boswellic acid & 0.6 to $7.1 \mu \mathrm{M} . / \mathrm{L}$ \\
\hline Ursolic Acid & $30 \mu \mathrm{M} / \mathrm{L}[13,14]$ \\
\hline
\end{tabular}

Table 1: Biological Activity of Natural Products.

\begin{tabular}{|l|l|l|l|l|l|l|l|l|}
\hline Parameters & Stretch & Bend & $\begin{array}{l}\text { Stretch- } \\
\text { Bend }\end{array}$ & Torsion & $\begin{array}{l}\text { Non-1,4 } \\
\text { VDW }\end{array}$ & $\mathbf{1 , 4 V D W}$ & $\begin{array}{l}\text { Dipole/ } \\
\text { Dipole }\end{array}$ & Total \\
\hline $\begin{array}{l}\text { Boswellic } \\
\text { Acid }\end{array}$ & 8.6522 & 16.8715 & 1.5198 & 23.9594 & -1.6231 & 26.1556 & 1.0477 & 76.5830 \\
\hline
\end{tabular}

Table 2: Parameters set for Boswellic acid.

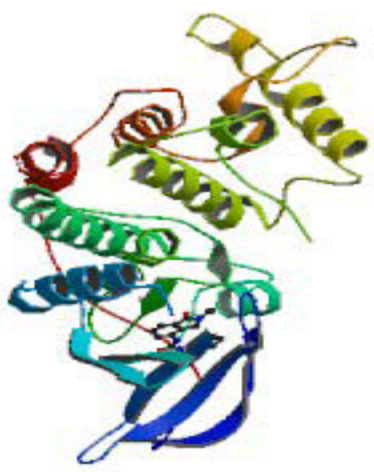

Figure 1: Structure of 1GII Enzyme with inhibitor.

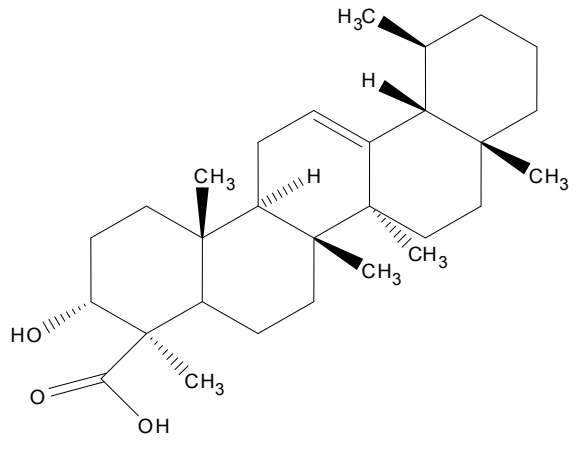

Figure 2: Boswellic Acid.

compounds in the binding site of human CDK2Protein, intermolecular flexible docking simulations were performed and energy values were calculated from the docked conformations of the CDK2 -inhibitor complexes. Docking studies yielded crucial information concerning the orientation of the inhibitors in the binding pocket of the target protein.

Docking results of the ligands and its derivatives via Arguslab docking software reveals that the e-value of two pentacyclic triterpenes i.e.; Boswellic acid (-22.55 and -18.59) showed better e values as compared to ursolic acid (unable to dock) with the receptor. Parameters which were set for boswellic acid given in table 2

Many amino acid residues interact with ligand boswellic acid as visible in figure 7. Docking of Boswellic acid with 1GII using Arguslab shows orientation of the boswellic acid in the binding pocket of $1 \mathrm{GII}$ target protein as visible in figure 8 . The amino acids residue of receptor 1 GII which undergo interaction with ligand Boswellic acid are 85 GLN, 132ASN, 86 ASP, 145ASP, 131GLN, 80 PHE 18VAL, 12 GLU and $11 \mathrm{GLY}$ as shown in figure 8.

\section{Results and Discussion}

The present study helps us to understand the interaction between the ligand and receptor CDK protein and also explore their binding mode. Docking study was performed using ArgusDock section available under 
Citation: Sanghani HV, Ganatra SH, Pande R (2012) Molecular-Docking Studies of Potent Anticancer Agent. J Comput Sci Syst Biol 5: 012-015. doi:10.4172/jcsb. 1000085

ArgusLab 4.0.1. The crystal structure of the CDK protein (1GII) was derived from PDB and used as a target for docking simulation shown in Figure 1 . The compounds selected from the literature are listed in Table 1. Ligand were created and prepared for the docking procedure using Chem Sketch and ArgusLab. The structures of the ligand obtained from the Chem Sketch are shown in Figure 2 and Figure 3.

Ligand boswellic acid and ursolic acid and 1GII protein as receptor were taken to explore their binding mode. Docking study was performed using Argus Dock section available under ArgusLab 4.0.1.

\section{Binding site of the protein}

The active site of 1GII comprises of amino acid residues such as 31 Alanine, 144Alanine, 132Aspargine, 86Aspartic acid, 145Aspartic acid, 85 Glutamin, 131 Glutamine, 81 Glutamic acid, 84 Histidine, 10 Isoleucine, 134 Leucine 33 Lysine, 80 Phenylalanine, 18 Valine, 64

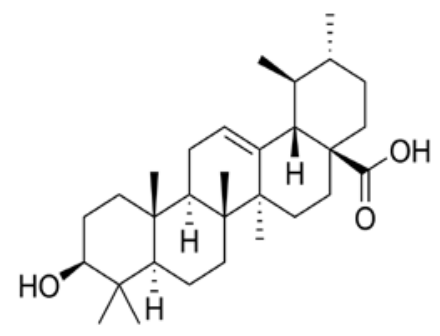

Figure 3: Ursolic acid.

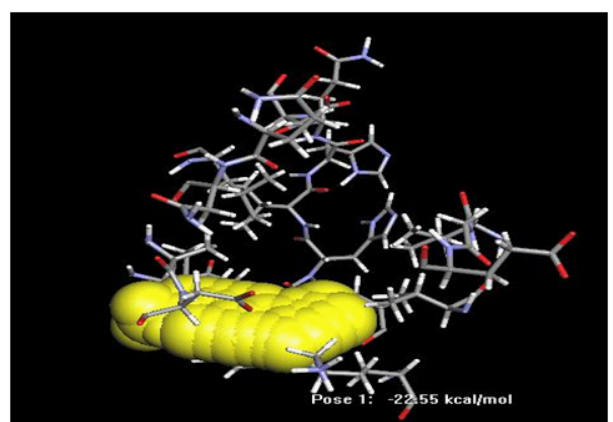

Figure 4: Docking of Boswellic acid in pose 1 with $1 \mathrm{G} \|$ using ArgusLab.
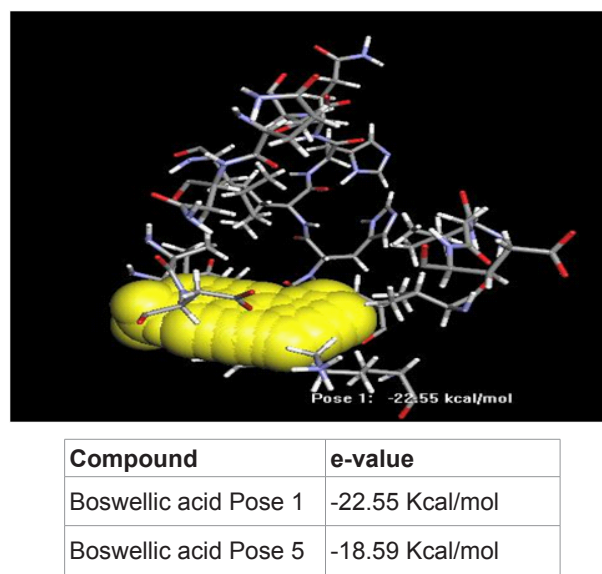

Figure 5: Docking of Boswellic acid in pose 5 with 1GII using ArgusLab.

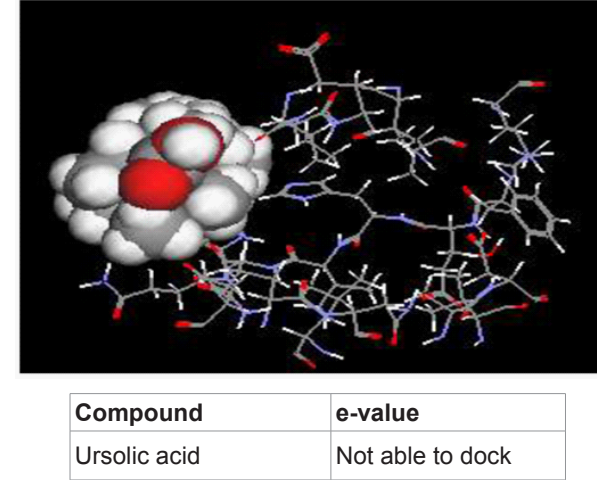

Figure 6: Docking of Ursolic acid using 1GIl with ArgusLab.

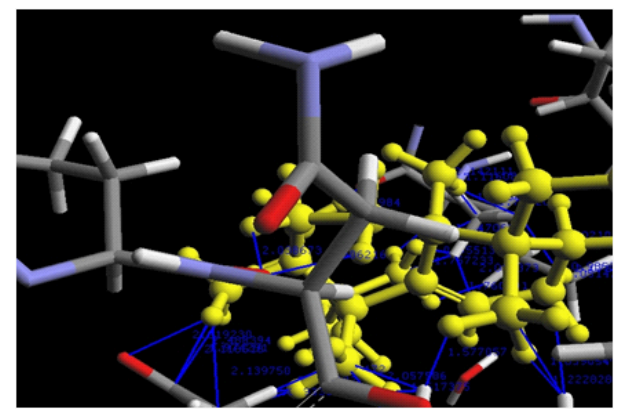

Figure 7: Docking of Boswellic acid with 1GII using Arguslab shows bond distances between amino acid and boswellic acid.

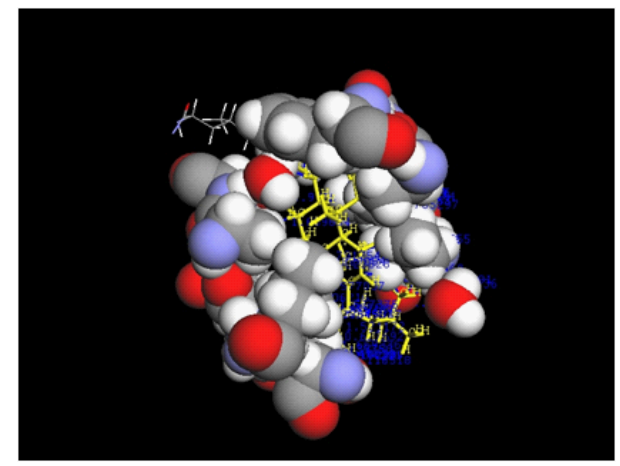

Figure 8: Docking of Boswellic acid with 1GII using Arguslab showing orientation of the boswellic acid in the binding pocket of $1 \mathrm{GI}$ target protein.

Valine, 83- Valine. As most of the amino acid residues in the active site are hydrophobic so they are the main contributors to the receptorligand interaction.

\section{Conclusion}

The Protein-Ligand interaction plays a significant role in structural based designing. In the present work we have taken the receptor Human cyclin dependent kinase 2 and identified a bioactive anticancer phytochemical. When the receptor (1GII) was docked with Boswellic acid the energy value obtained was $(-22.55 \mathrm{k} \mathrm{cal} / \mathrm{mol})$ using ArgusLab. When Ursolic acid was docked against the same receptor it was unable to dock. From this we conclude that from both pentacyclic triterpenes Boswellic acid is better anticancer phytochemical than ursolic acid. 
Citation: Sanghani HV, Ganatra SH, Pande R (2012) Molecular -Docking Studies of Potent Anticancer Agent. J Comput Sci Syst Biol 5: $012-015$. doi:10.4172/jcsb. 1000085

In this study, the molecular docking was applied to explore the binding mechanism and to correlate its docking score with the activity of plant derived compounds. The results of our present study can be useful for the design and development of novel compounds having better inhibitory activity against several type of cancer. This potential agent will be a promising candidate can further be validated in wet lab studies for its proper function.

In future research work the ADME/T (Absorption, Distribution, Metabolism, Excretion/Toxicity) properties of these compounds can be tested in wet lab and research can proceed for clinical trials [17].

\section{Acknowledgment}

The support of Department of Chemistry, Institute of Science, Nagpur (M.S) \& School of studies Chemistry Department Pt.Ravishankar Shukla University, Raipur (M.P) are gratefully acknowledged.

\section{References}

1. Cancer Incidence in Five Continents, Volumes I TO IX. Lyon: International Agency for Research on Cancer (IARC Scientific Publications).

2. Hartwell JL (1969) Plants used against cancer. A survey. Lloydia 32: 247-296.

3. Hartwell JL (1969) Plants used against cancer. A survey. Lloydia 32: 153-205.

4. Hartwell JL (1969) Plants used against cancer. A survey. Lloydia 32: 78-107.

5. Hartwell JL (1970) Plants used against cancer. A survey. Lloydia 33: 288-392.
6. Hartwell JL (1970) Plants used against cancer. A survey. Lloydia 33: 97-194

7. Hartwell JL (1971) Plants used against cancer. A survey. Lloydia 34: 386-425.

8. Hartwell JL (1971) Plants Used Against Cancer. A Survey. Lloydia 34: 204-255

9. Hartwell JL (1971) Plants used against cancer. A survey. Lloydia 34: 310-361.

10. Hartwell JL (1971) Plants used against cancer. A survey. Lloydia 34: 103-160.

11. Pandey G (2002) Anticancer herbal drugs of India with special reference to Ayurveda. New Delhi: Sri Satguru Publications: 18-121.

12. Yan Qiu Meng, Lin Xiang Zhao, Zan Wang, Dan Liu, Yong Kui Jing (2005) Synthesis of Boswellic Acid Derivatives and Primary Research on their Activities. Chin Chem Lett 16: 867-870.

13. Jie Li, Wei-Jian Guo, Qing-Yao Yang (2002) Effects of ursolic acid and oleanolic acid on human colon carcinoma cell line HCT15. World J Gastroenterol 8: 493495.

14. Novotný L, Vachálková A, Biggs D (2001) Ursolic acid: an anti-tumorigenic and chemopreventive activity. Minireview. Neoplasma 48: 241-246.

15. Srivastava V, Kumar A, Mishra BN, Siddiqi MI (2008) Molecular docking studies on DMDP derivatives as human DHFR inhibitors. Bioinformation 3: 180-188.

16. Miteva MA, Violas S, Montes M, Gomez D, Tuffery P, et al. (2006) FAFDrugs: free ADME/tox filtering of compound collections. Nucleic Acids Res 34 W738-W744.

17. http://www.pharma-algorithms.com/webboxes/. 